Vol. 11 (4): 995-1000 (2021)

\title{
INFLUENCE OF PRODUCTION TRANSPORT ON PHYSIOLOGICAL STATE OF BROILER CHICKENS
}

\author{
Lyudmila K. Buslovskaya $^{1^{*}}$, Alexey Yu. Kovtunenko ${ }^{1}$ \\ ${ }^{1 *}$ Belgorod State University, Russia, 308015, Belgorod, Pobedy street, 85, Russia; \\ *Corresponding Author Lyudmila K. Buslovskaya, e-mail: Buslovskaya@ bsu.edu.ru;
}

Received August 2021; Accepted September 2021; Published October 2021;

DOI: https://doi.org/10.31407/ijees11.444

\begin{abstract}
In present research work, the effect of transportation and related factors on broiler chicken organism of the Hubbard F15 cross studied. Based on the analysis of leukogram parameters, leukocyte index dynamics, it was established that the transportation of poultry is characterized by a complex effect, leading to developing a stress reaction. Significant alterations in leukogram parameters (eosinophils, lymphocyte content decrease, the number of segmented lymphocytes, and leukocyte index increase) indicating the stress state of chickens are detected already 10 hours after the onset of exposure to a complex of transport factors.
\end{abstract}

Keywords: transportation, stress, Adaptation, leukogram, vibration, leukocyte indices, broiler chickens. 